\title{
Oxygen Transport in the Intact Hypoxic Newborn Lamb: Acute Effects of Increasing $P_{50}$
}

\author{
GEORGE LISTER ${ }^{(30)}$ \\ Department of Pediatrics and Anesthesia, Yale University School of Medicine, 333 Cedar Street, New Haven \\ Connecticut, USA
}

\begin{abstract}
Summary
We examined the acute effects of a change in hemoglobin oxygen affinity $\left(P_{50}\right)$ on systemic oxygen transport and oxygen consumption during hypoxia. Ten awake, intact, newborn lambs were studied during four consecutive conditions: normoxia $\left(\mathrm{FIO}_{2}\right.$ $=0.21)$; hypoxia $\left(\mathrm{FrO}_{2}=0.10\right)$; hypoxia after isovolemic exchange transfusion, raising $P_{50} 8 \pm 3$ Torr without changing hematocrit; and normoxia after the exchange transfusion. With hypoxia, oxygen extraction rose, cardiac output increased minimally, and systemic oxygen transport and oxygen consumption fell. After exchange transfusion during hypoxia, oxygen consumption rose to resting levels due to a significant augmentation of systemic oxygen transport, which resulted from an increase in cardiac output. This change in cardiac output was due to an increased stroke volume, most likely due to an improved inotropic state. The above findings are consistent with observations in newborn infants with respiratory distress syndrome who underwent exchange transfusion.
\end{abstract}

\section{Abbreviations}

CPD, buffered citrate phosphate dextrose $\dot{\mathrm{V}}_{\mathrm{O}_{2}}$, whole body oxygen consumption of uptake

$\dot{\mathrm{V}}_{\mathrm{O}_{2}}$ is generally a reflection of metabolic needs and is usually not dependent on oxygen supply or transport. At rest, the systemic oxygen delivery or transport (the product of cardiac output and arterial oxygen content) is in great excess of oxygen uptake (the product of cardiac output and arteriovenous oxygen content difference) $(22,23)$. Moderate perturbations of oxygen supply are, therefore, well tolerated without consequence for oxygen consumption $(8,28)$. On the other hand, when oxygen supply is severely curtailed as may occur with profound decreases in arterial oxygen content, oxygen consumption may fall below resting levels $(5,12,21)$. At this point, the relationship between oxygen supply and oxygen uptake becomes linear, suggesting that oxygen uptake is now limited by transport $(3,4)$. As such, it has been demonstrated in adult animals that oxygen consumption may be decreased by severe anemia or hypoxia.

In the face of a fall in arterial oxygen content, oxygen consumption might be maintained at a constant level by a compensatory increase in cardiac output or by an increase in the proportion of arterial oxygen that is extracted (27). The newborn of a species, however, might be at particular risk for compromising oxygen uptake under these conditions because of a limited ability to increase cardiac output above resting levels (16), and a high hemoglobin oxygen affinity that may impair oxygen extraction (22). In concert with this was the finding that oxygen consumption fell below resting levels in anesthetized newborn lambs whereas there was no change in oxygen consumption in ewes with comparable levels of alveolar hypoxia (5). In view of this observation, we questioned whether decreasing hemoglobin oxygen affinity in an hypoxic newborn would allow more of the transported oxygen to be extracted, thereby helping to restore oxygen uptake to near resting levels. To study this, we used the newborn lamb as a model, and during a period of hypoxia we altered hemoglobin oxygen affinity by exchange transfusion using adult sheep blood, while monitoring oxygen transport and uptake.

\section{MATERIALS AND METHODS}

Subjects. Ten healthy lambs (1-7-d-old) of mixed breed were studied. Their weight at the time of study was $5.7 \pm 1.4 \mathrm{~kg}(\mathrm{~m} \pm$ SD).

Preparation. Using local lidocaine analgesia, tygon catheters were placed in the right carotid artery and right jugular vein by an incision in the neck. One venous catheter was advanced into the pulmonary artery while the pressure tracing was monitored to ensure proper placement. A second catheter was passed into the right ventricle and withdrawn slowly into the right atrium. The arterial catheter was advanced into the left ventricle and then withdrawn so that it remained in the aorta. The catheters were tunneled subcutaneously and brought out through a small incision in the flank. The lambs were returned to their mothers and permitted to recover for at least $12 \mathrm{~h}$ before the study. In three of the lambs at the time of the study, a thermistor was passed through a percutaneous venous cannula in the hind leg and advanced into the inferior vena cava. This was used to monitor core temperature.

Protocol. At the time of study, the lamb was removed from the ewe and placed in a canvas sling so that it might rest comfortably in an upright position. A face mask was placed over the snout and a large reservoir bag was used to cover the face mask and the head so that inspired oxygen concentration could be controlled and oxygen consumption could be measured continuously. Simultaneous with the measurement of oxygen consumption we could intermittently sample blood from the pulmonary artery, right atrium, and the aorta, and we could monitor corresponding vascular pressures (Fig. 1). The lambs were studied in a room in which the temperature was $24-26^{\circ} \mathrm{C}$. No attempt to provide additional temperature control of the lambs was made.

While the animals were at rest, unsedated, and breathing room air, control measurements were made of oxygen consumption, vascular pressures, heart rate, hemoglobin concentration, arterial and mixed systemic venous oxygen saturations and blood gases, and oxygen hemoglobin affinity or $\mathrm{P}_{50}$, the $\mathrm{PO}_{2}$ at $50 \%$ hemogiobin saturation ( $\mathrm{pH} 7.40 \mathrm{PCO}_{2} 40$ torr, temperature $39^{\circ} \mathrm{C}$ ). From this, cardiac output and data for oxygen transport were calculated. The animals were maintained in the control state for at least $30 \mathrm{~min}$ to get stable resting values. After this, the inspired oxygen concentration was acutely lowered to 0.10 ; once the animals were stabilized, similar data were obtained. From prelim- 


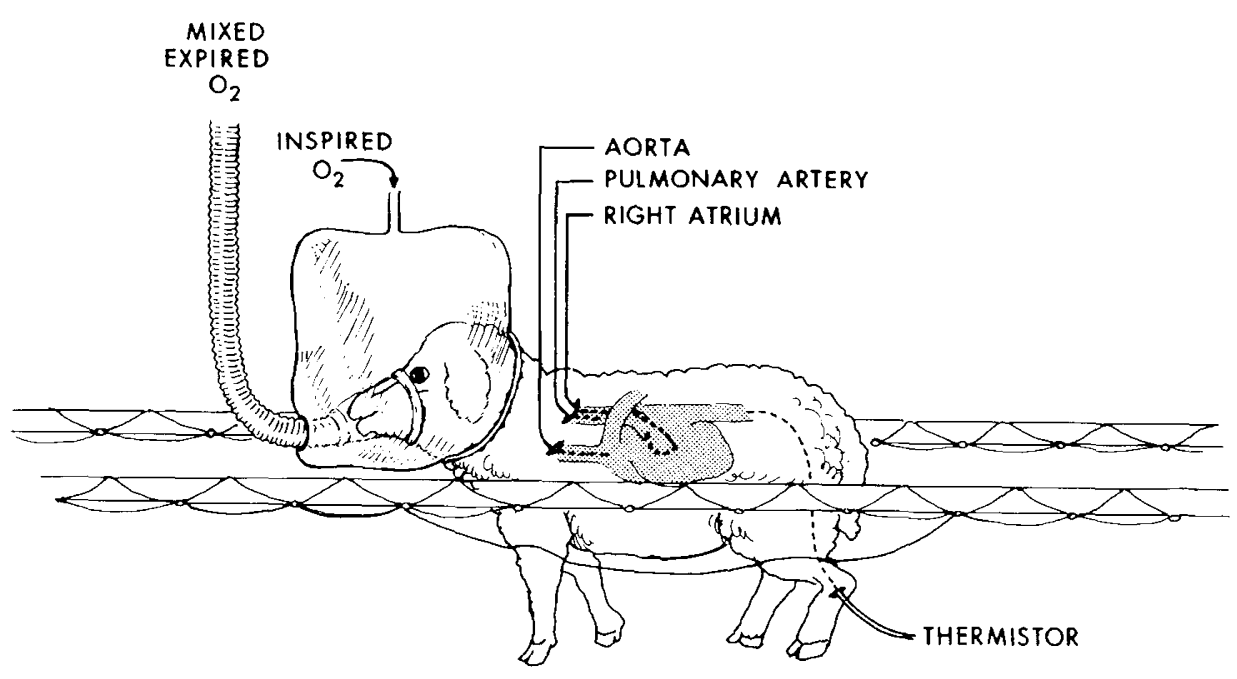

Fig. 1. Representation of lamb during study. See text for description.

inary studies, we confirmed that oxygen consumption would be consistently lowered below basal levels by this degree of alveolar hypoxia. While the animals were still hypoxic, they underwent an isovolemic exchange transfusion equivalent to approximately twice their blood volume (estimated at $80 \mathrm{cc} / \mathrm{kg}$ ) using fresh adult blood. This was intended to decrease hemoglobin oxygen affinity without changing hemoglobin concentration or blood volume. For transfusion, fresh sheep blood which was stored in heparin (seven studies) or CPD (three studies) was passed through a microaggregate filter (Pall Biomedical Products, Glen Cove, NY) and warmed to body temperature using a blood/fluid warmer (Gormann-Rupp Industries, Belleville, $\mathrm{OH}$ ). The three lambs transfused with blood collected in CPD were given intravenously, $100 \mathrm{mg} 10 \%$ calcium gluconate per $100 \mathrm{cc}$ of transfused blood. In these three lambs, ionized calcium was measured before and after transfusion and the calcium replacement restored values to pre-exchange levels.

After exchange transfusion, the lambs were kept hypoxic for at least $30 \mathrm{~min}$. At the end of this period, oxygen consumption, cardiac output, and arterial venous oxygen content difference were again measured. After hypoxia, the lambs were returned to a normoxic environment and similar data obtained. The entire study was approximately $3 \mathrm{~h}$, but this varied from animal to animal because we waited for each animal to be resting and quiet for at least $15 \mathrm{~min}$ before proceeding with each subsequent stage of the study period. During a 15 -min period when the lambs were stable, data were collected on three occasions (approximately 5-min intervals) and averaged to provide a single value for each lamb at each study period; thus, each lamb served as its own control.

In two additional lambs, the entire procedure was followed as previously described except blood for transfusion was taken from a twin sibling so that neither hemoglobin oxygen affinity nor hemoglobin concentration was altered. These two studies were intended to detect any methodologic biases introduced by the procedure of transfusion. As with the other lambs, oxygen consumption and oxygen transport decreased in these two lambs with hypoxia, but there was no change in these variables after exchange transfusion. It is therefore unlikely that the procedure contributed to the physiologic changes observed in the other 10 lambs.

Measurements. Our methods were described and confirmed in a prior report (22). Briefly, oxygen consumption was measured by a flow-through system permitting continuous sampling of a mixture of the expired gas and the inspired air drawn through the face mask. Blood gas tensions were measured by standard electrodes and corrected to $39^{\circ} \mathrm{C}$, the normal body temperature of sheep. Hemoglobin oxygen saturation was measured by a micro-oximeter and hemoglobin was measured by the cyanmethemoglobin method. Oxygen contents were calculated from the oxygen carrying capacity of hemoglobin $\left(1.36 \mathrm{ml} \mathrm{O}_{2} / \mathrm{g} \mathrm{Hb}\right)(22)$, oxygen saturation, and dissolved oxygen. Although there are likely small errors introduced by correcting all blood gases to $39^{\circ} \mathrm{C}$ rather than actual body temperature, this has no consequence for the calculations of oxygen content or variables related to oxygen transport. $\mathrm{P}_{50}$ was calculated from hemoglobin oxygen and oxygen tension measured in the same sample of blood and corrected to $\mathrm{pH} 7.40, \mathrm{PCO}_{2} 40$ torr, $39^{\circ} \mathrm{C}$.

Cardiac output was calculated by the Fick method using the measured oxygen consumption and the arteriovenous oxygen content difference (AVD). By comparison of the right atrial and pulmonary arterial oxygen tensions, there was no evidence of a patent ductus arteriosus in any of the lambs so that systemic and pulmonary blood flows were equal. Systemic oxygen transport (SOT) was calculated as the product of cardiac output $(\mathrm{CO})$ and arterial oxygen content $\left(\mathrm{CaO}_{2}\right)$. Coefficient of oxygen extraction or the proportion of systemic oxygen transport that is consumed was derived from oxygen contents as follows:

$$
\text { Coeff of Extr }=\frac{\dot{\mathrm{V}}_{\mathrm{O}_{2}}}{\mathrm{SOT}}=\frac{\mathrm{CO} \times\left(\mathrm{CaO}_{2}-\mathrm{CvO}_{2}\right)}{\mathrm{CO} \times \mathrm{CaO}_{2}}=\frac{\mathrm{AVD}}{\mathrm{CaO}}
$$

Oxygen transport data were compared under each of the four conditions by analysis of variance. When significant differences existed among the means, data were compared by paired $t$ test as follows: control normoxia versus final normoxia, control normoxia versus initial hypoxia, initial hypoxia versus hypoxia after exchange transfusion. Because each value was used for two such comparisons, we corrected for the increased likelihood of falsely rejecting the null hypothesis (type I error) with multiple comparisons. To do this, we tested data at the 0.025 level but only report it to the $0.025 \times 2$, or 0.05 level of significance (25).

\section{RESULTS}

The data for 10 lambs under the four experimental conditions are summarized in Table 1 . The data for the lambs that underwent exchange transfusion with blood from donor twins are not included here and are mentioned below. All lambs remained stable during the experimental periods and none required medications or any resuscitative measures to support their circulation. The hemodynamic and oxygen transport data at rest under the initial normoxic conditions are quite comparable to our previous results (22). With hypoxia, oxygen consumption fell in all animals, although the degree to which this occurred varied considerably. This was associated with a large fall in systemic oxygen transport and increase in the coefficient of oxygen extraction. 
Table 1. Summary of oxygen transport data for 10 lambs during four experimental conditions*

\begin{tabular}{|c|c|c|c|c|}
\hline & Normoxia & Hypoxia & $\begin{array}{c}\text { Hypoxia }+ \\
\text { exchange } \\
\text { transfusion }\end{array}$ & Normoxia \\
\hline $\mathrm{Hct}$ & $28 \pm 3$ & $29 \pm 2^{u}$ & $31 \pm 3$ & $31 \pm 4 \dagger^{c}$ \\
\hline$P_{50}$ & $27.0 \pm 3.9$ & $27.0 \pm 3.9$ & $35.5 \pm 3.0 t^{h}$ & $35.5 \pm 3.0 \div$ \\
\hline $\mathrm{PaO})_{2}$ & $81 \pm 12$ & $31 \pm 4$ & $31 \pm 5$ & $94 \pm 13+$ \\
\hline $\mathrm{pHa}$ & $7.39 \pm 0.04$ & $7.44 \pm 0.04 ; \mathrm{\dagger aa}$ & $7.43 \pm 0.05$ & $7.41 \pm 0.04$ \\
\hline $\mathrm{PaCO}_{2}$ & $31 \pm 2$ & $27 \pm 4 \uparrow^{\prime \prime}$ & $26 \pm 3$ & $30 \pm 3$ \\
\hline $\mathrm{SaO}_{2}$ & $0.95 \pm 0.02$ & $0.47 \pm 0.08 \dagger^{a}$ & $0.39 \pm 0.11 \dagger^{h}$ & $0.94 \pm 0.02$ \\
\hline $\mathrm{CaO}_{2}$ & $11.23 \pm 1.32$ & $6.07 \pm 1.17 t^{a}$ & $5.31 \pm 1.06 t^{b}$ & $12.48 \pm 1.70$ \\
\hline $\mathrm{PvO})_{2}$ & $36 \pm 5$ & $19 \pm 6 \dagger^{\circ}$ & $17 \pm 3$ & $38 \pm 5$ \\
\hline$A V D$ & $4.91 \pm 0.78$ & $3.90 \pm 0.77 \dagger^{a}$ & $3.74 \pm 0.88$ & $5.60 \pm 0.92 \dagger$ \\
\hline$\dot{\mathrm{V}}_{\mathrm{O}_{2}}$ & $17.5 \pm 3.1$ & $14.6 \pm 2.0 \dagger^{a}$ & $17.8 \pm 3.2 t^{\prime \prime}$ & $18.5 \pm 3.8$ \\
\hline $\mathrm{CO}$ & $361 \pm 55$ & $390 \pm 66$ & $506 \pm 166 \dagger^{h}$ & $338 \pm 39$ \\
\hline SOT & $40.7 \pm 9.5$ & $23.2 \pm 5.0 \uparrow^{a}$ & $26.5 \pm 4.5 t^{h}$ & $41.5 \pm 7.4$ \\
\hline Cocff Extr & $0.438 \pm 0.071$ & $0.647 \pm 0.121 \dagger^{\prime \prime}$ & $0.686 \pm 0.080$ & $0.459 \pm 0.100$ \\
\hline $\mathrm{HR}$ & $227 \pm 51$ & $260 \pm 52 \dagger^{a}$ & $260 \pm 54$ & $239 \pm 55$ \\
\hline SV & $1.66 \pm 0.47$ & $1.64 \pm 0.54$ & $2.03 \pm 0.67 \dagger^{\prime \prime}$ & $1.52 \pm 0.49$ \\
\hline CVP & $-1 \pm 4$ & $-1 \pm 4$ & $0 \pm 4$ & $0 \pm 4$ \\
\hline$P_{A 0}$ & $75 \pm 9$ & $73 \pm 11$ & $74 \pm 15$ & $78 \pm 12$ \\
\hline SVR & $230 \pm 55$ & $202 \pm 45 t^{\prime \prime}$ & $163 \pm 62 t^{h}$ & $238 \pm 63$ \\
\hline
\end{tabular}

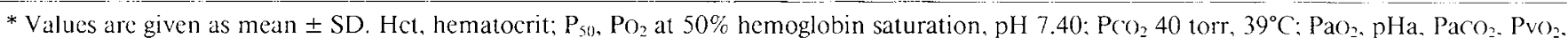
arterial and mixed venous blood gases in torr or $\mathrm{mm} \mathrm{Hg:} \mathrm{CVP.} \mathrm{central} \mathrm{venous} \mathrm{pressure} \mathrm{and} \mathrm{P}_{\mathrm{Ao}}$. mean aortic pressure are both in torr or $\mathrm{mm} \mathrm{Hg}$ : $\mathrm{SaO}_{2}$, arterial oxygen saturation; $\mathrm{CaO}_{2}$, arterial oxygen content and $\mathrm{AVD}$, arteriovenous oxygen content difference in $\mathrm{ml} \mathrm{O}_{2} / \mathrm{dl}_{;} \dot{\mathrm{V}}_{\mathrm{O}_{2}}$ in $\mathrm{ml} \mathrm{O}_{2} \cdot \mathrm{min}{ }^{-1}$.

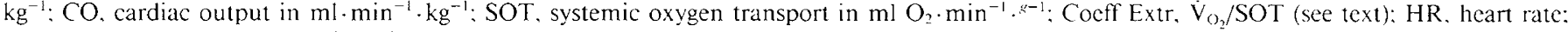
$\mathrm{SV}$, stroke volume in $\mathrm{ml} \cdot \mathrm{min}^{-1} \cdot \mathrm{kg}^{-1}$; and $\mathrm{SVR}$, systemic vascular resistance in $\mathrm{mm} \mathrm{Hg} \cdot \mathrm{L}^{-1} \cdot \mathrm{min} \cdot \mathrm{kg}$.

$\dagger$ Statistically significant differences $(P<0.05)$ are shown as ${ }^{a}$ Normoxia $v s$ Hypoxia, ${ }^{b}$ Hypoxia $v s$ Hypoxia + exchange transfusion, and ${ }^{c}$ Initial normoxia is Final normoxia (after the exchange transfusion).

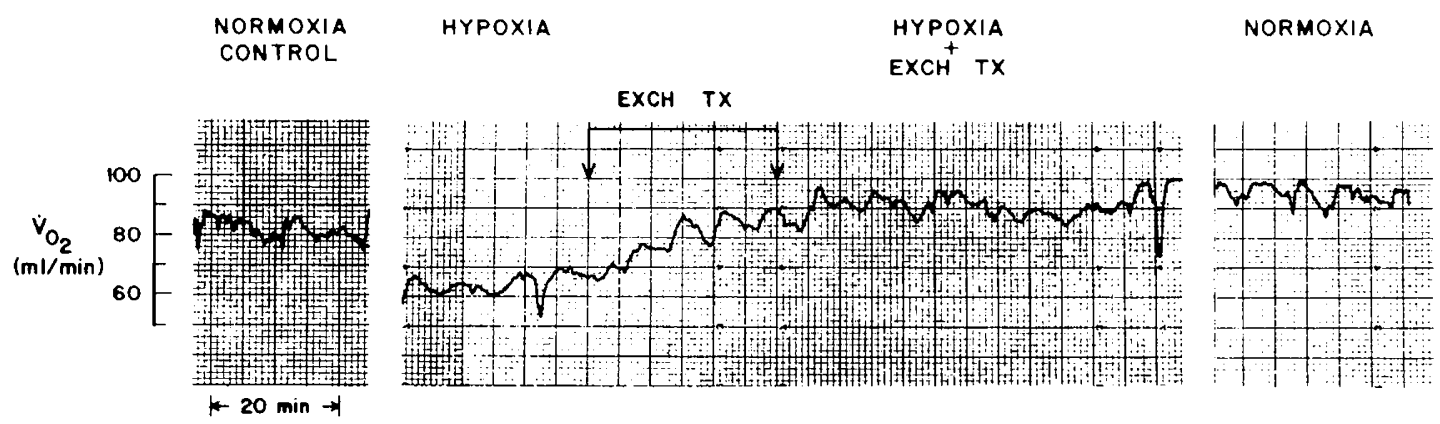

Fig. 2. Recording of oxygen consumption in single lamb during four experimental conditions. Although there were fluctuations in the $\dot{V}_{()_{2}}$. changes from one period to another were well out of the range of this variability and the increase in $\dot{V}_{\mathrm{O}_{2}}$ after exchange transfusion (Exch Tx) was sustained throughout hypoxia.

Cardiac output increased in nine of the 10 lambs during hypoxia. This was generally a small increase, and was roughly proportional to the rise in heart rate, i.e., stroke volume was unchanged. There was a profound fall in arterial oxygen content and a lesser decrease in mixed venous oxygen content, so the arterial venous oxygen content difference decreased.

With exchange transfusion, $\mathrm{P}_{50}$ increased $8 \pm 3$ torr $(\mathrm{m} \pm$ S.D.) as anticipated, with no significant change in hematocrit. There was an increase in systemic oxygen transport with exchange transfusion with an increase in oxygen consumption in all lambs to near initial normoxic levels (Fig. 2 and Table 1). These changes in oxygen transport were concomitant with a large increase in cardiac output with no associated change in central venous pressure, heart rate, or aortic systolic, diastolic or mean pressures, but with a significant augmentation of stroke volume.

As one would expect from the alveolar gas equation, arterial oxygen tension did not change with the exchange transfusion, but arterial oxygen saturation fell due to the rightward shift of the hemoglobin oxygen equilibrium curve. Mixed venous oxygen tension stayed constant but there was a fall in oxygen saturation here also. Although arteriovenous oxygen content difference fell further after exchange transfusion, the proportional oxygen extraction remained unchanged.

Once lambs were again placed in a normoxic environment, hemodynamic and oxygen transport data returned to near control levels, although oxygen consumption was slightly higher as has been noted by others (4). There was also an increased arteriovenous oxygen content difference and lower cardiac output during this period, and this is comparable to what has been reported with an experimental increase in $P_{50}$ under normoxic conditions without interposed hypoxia (6).

Due to the wide biologic variability under all conditions, data for oxygen transport were also normalized to the initial normoxic period, using each lamb as its own control. These data were then broken down into the factors contributing to the changes in oxygen consumption and these are displayed in Figure 3.

During hypoxia, after the abrupt fall in oxygen consumption core temperature decreased slowly to about $1^{\circ} \mathrm{C}$ below basal levels. After exchange transfusion, core temperature slowly rose to its initial value.

In Figures $4 \mathrm{~A}$ and $\mathrm{B}$ cardiac outputs are shown as a function of arterial oxygen saturation. The data points in A represent all 


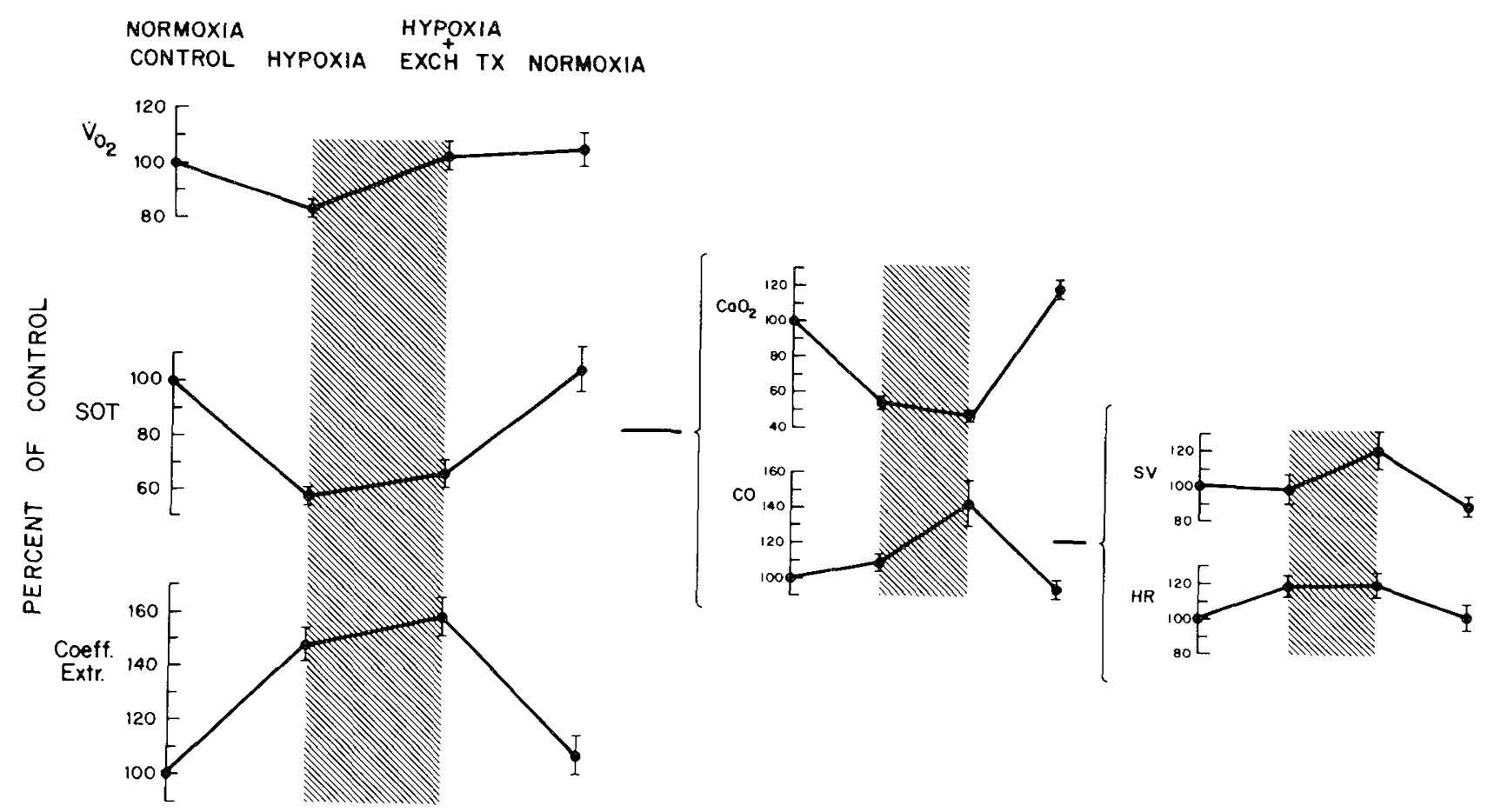

Fig. 3. Changes contributing to augmentation of oxygen consumption after exchange transfusion (Exch Tx) during hypoxia. Data for each lamb were divided by the initial value, i.e. normoxia control to normalize them. These normalized data were averaged and are presented as mean \pm SE. Note that $\dot{\mathrm{V}}_{\mathrm{O}_{2}}=\mathrm{SOT} \times$ Cocff Extr; SOT $=\mathrm{CaO}_{2} \times \mathrm{CO}$; and $\mathrm{CO}=\mathrm{HR} \times \mathrm{SV}$

the individual values for each lamb under each condition. Because at least three measurements of cardiac output and oxygen saturation were taken for each lamb during each condition, there are over 120 points here. Changes in cardiac output that occurred during hypoxia with exchange transfusion are shown in $4 \mathrm{~B}$. Because arterial oxygen tension did not change with exchange transfusion, arterial saturation fell and, as is shown, cardiac output increased in nine of the 10 lambs. For this figure, the cardiac output data during pre-exchange hypoxia for a given lamb were averaged, as were those postexchange.

\section{DISCUSSION}

The finding of a decrease in oxygen consumption in newborn lambs during hypoxia was consistent with previous work by Cross et al. (5); however, the oxygen consumption during normoxia was higher in our study and the degree to which oxygen consumption fell with hypoxia was much greater than they noted. At least two factors may help account for this: their lambs were anesthetized and external warmth was provided. These measures no doubt lowered the resting needs for oxygen, and may have provided the lambs with more reserve for maintaining oxygen consumption under stress. Furthermore, the degree of decrease in oxygen consumption during hypoxia in their study was greater in the lambs with the higher initial level.

The decrease in oxygen consumption at this level of hypoxia occurs in the presence of a large fall in systemic oxygen transport in the newborn lamb; arterial oxygen content falls substantially and cardiac output remains constant or increases only minimally $(7,24)$, as seen here. In contrast, with comparable levels of hypoxia in adult sheep (5) or dogs (1), cardiac output usually increases considerably, although this response is blunted if hyperventilation and hypocapnia are prevented (18). In studies of anesthetized adult dogs during both anemic and hypoxic hypoxia, Cain has shown that oxygen consumption does not fall until oxygen transport reaches the range of $10 \mathrm{ml} \cdot \mathrm{kg} \cdot{ }^{-1} \cdot \mathrm{min}^{-1}$, suggesting that this might be a critical level of oxygen transport $(2,3)$. In our study, oxygen consumption in the lambs fell at a level of oxygen transport well in excess of this. Certainly, the awake newborn with high resting metabolic rate must need an oxygen transport considerably higher than that of an adult (19).

Although the oxygen needs of an organ such as the heart undergoing mechanical work $(10,13)$ can be assessed, at present there is no means to judge a priori the oxygen needs for the whole body under various conditions. In addition, there is no clear marker for the point where oxygen needs are no longer being sufficiently met. For our study, we have assumed that any fall in oxygen consumption below the minimal level at rest and associated with a decrease in oxygen transport without a comparable decrease in demands represents an insufficiency of oxygen supply (14). We have tried to ensure that oxygen demands were constant by only reporting the data when the animal was quiet, resting, and demonstrating minimal variation in oxygen consumption and by controlling the ambient temperature. In addition, we found that with experimental manipulations the change into oxygen consumption was well out of the range of the minor fluctuations seen at rest (Fig. 2). The fact that there was no change in oxygen transport during hypoxia in the lambs receiving a twin transfusion suggests that the increases in cardiac output and oxygen consumption seen here were not artifacts of the methods, but were related in some manner to the experimental manipulations. Finally, it is important to note that any increase in myocardial oxygen consumption attendant with the rise in cardiac output would be an order of magnitude less than the changes in whole body oxygen consumption seen and, therefore, cannot account for our findings $(9,10,20)$.

Because oxygen consumption in the presence of arterial hypoxemia may be preserved by increasing systemic oxygen transport through an augmented cardiac output or by increasing the proportion of transported oxygen that is extracted, one might also expect that either of these measures might help restore a subnormal oxygen consumption. This was certainly our initial hypothesis when we altered hemoglobin oxygen affinity intending to enhance oxygen extraction. There are some theoretical reasons, however, why shifting hemoglobin oxygen equilibrium to the right (increasing $\mathrm{P}_{s_{0}}$ ) may not increase extraction at very 

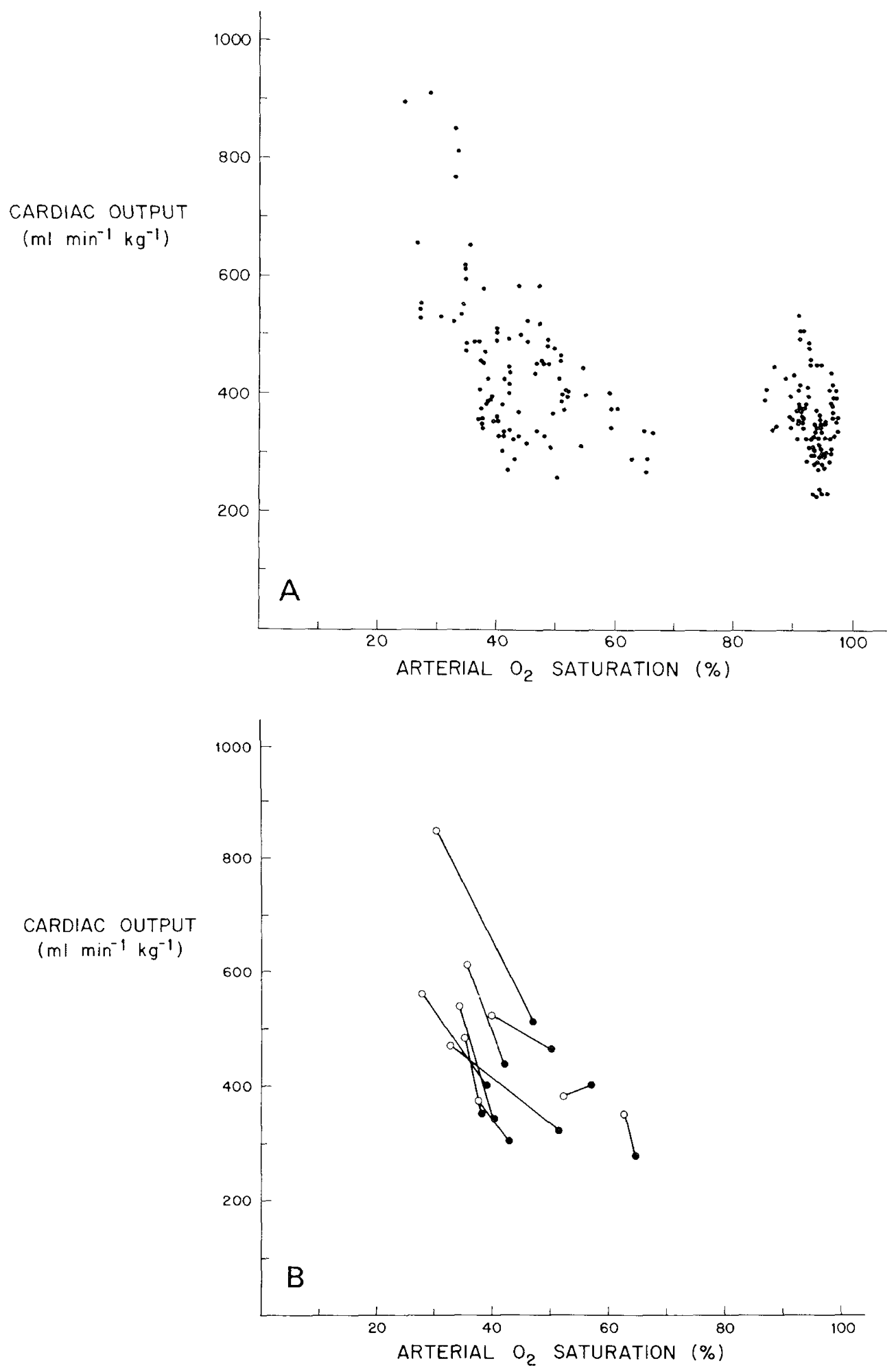

Fig. 4. (A) Cardiac output shown in relation to arterial oxygen saturation. (B) Cardiac output during hypoxia shown in relation to arterial oxygen saturation before (closed circles) and after (open circles) exchange transfusion. Lines connect values for individual lambs and represent changes in cardiac output with alterations in oxygen saturation at constant $\mathrm{PaO}_{2}$ (due to the rightward shift of the hemoglobin oxygen equilibrium curve, i.e., with an increase in $\mathrm{P}_{50}$ ).

severe levels of hypoxia. If arterial and mixed venous oxygen tensions are fixed, a rightward shift may decrease arterial oxygen content without a comparable change in venous content, thereby decreasing arteriovenous oxygen content difference and proportional extraction (26). This fact not withstanding, we thought it worth investigating the potential for increasing oxygen extraction by exchanging fetal for adult hemoglobin; however, in this study the percent oxygen extraction was not changed during hypoxia by the increase in $\mathrm{P}_{50}$, nor was the arteriovenous oxygen content difference. One could not have predicted the actual change in arteriovenous oxygen content difference with the alteration in oxyhemoglobin affinity because the exact level to which mixed venous oxygen tension falls is not known in advance. What was surprising here was that the augmented oxygen consumption 
with exchange transfusion was due to an increase in cardiac output and systemic oxygen transport.

To explore the cause for the increase in cardiac output, we examined the various determinants of myocardial performance. The rise in cardiac output after exchange transfusion during hypoxia was associated with a sustained high heart rate, an increase in stroke volume, and a constant arterial pressure. Of interest is that such a rise in cardiac output in hypoxic lambs given adult blood has also been observed previously although it was not discussed or explored further (7). An increase in the enddiastolic volume might have produced such a rise in stroke volume, but there are three findings that mitigate against this as a significant factor: $I$ ) all transfusions were done as an isovolemic exchange; 2) central venous pressure did not change with exchange transfusion (although we recognize the pressure-volume relationship in the atrium may be flat); and 3) cardiac output upon return to normoxia was below control levels, as has been seen with a change in hemoglobin oxygen affinity without the interposed period of hypoxia (6). We would not expect cardiac output to be lower than the initial control, if the lambs had been inadvertently volume expanded. The other factor that might have increased stroke volume is a change in the inotropic state, either neurally or humorally mediated (17). From the relationship between arterial oxygen saturation and cardiac output, we might speculate that the augmentation of cardiac output was due to stimulation of a chemoreceptor responsive to oxygen content or saturation $(15,19)$. The additional fall in arterial oxygen saturation during hypoxia with the rightward shift of the hemoglobin oxygen equilibrium curve may have increased such a chemoreceptive stimulus, be it centrally or peripherally mediated $(17,19)$. Commensurate with this speculation was the finding that cardiac output was increased as arterial oxygen saturation decreased at a constant arterial $\mathrm{P}_{\mathrm{O}_{2}}$, (Fig. 3B).

A recent clinical study in newborn infants with respiratory distress syndrome also reflects on our findings (11). Infants underwent exchange transfusion with adult blood, and these patients had a significantly lower mortality than mathced controls. The authors noted that throughout the period of exchange transfusion there was a consistent progressive rise in arterial oxygen tension. The cause of this was not certain, but an increase in pulmonary perfusion (cardiac output) was suggested, which would be entirely commensurate with our data.

Why the newborn does not increase cardiac output to meet oxygen needs in response to hypoxia is still uncertain. It is clear from previous studies that the newborn has enough reserve to increase cardiac output at least $30-40 \%$ above resting levels (16). Whether with exchange transfusion the additional fall in arterial oxygen content causes chemoreceptor stimulation and/or release of catecholamines is unresolved at present. It is quite possible that the beneficial effects that have been seen with exchange transfusion here and in human infants are mediated in part by an augmentation of cardiac output, thereby allowing oxygen transport and supply to meet demands and acutely restoring oxygen consumption to near resting levels. It remains to be determined how sustained these effects may be and what role a change in change in hemoglobin oxygen affinity plays in maintaining the delicate balance between oxygen supply and uptake in the hypoxic newborn.

\section{REFERENCES AVD NOTES}

1. Adachi, H Strauss. H. W. Ochi, H and Wagner, H. N Jr: The effect of hypoxia on the regional distribution of cardiac output in the dog. Circ. Res. 39: $314(1976)$

2. Cain, S. M.: Appearance of excess lactate in anesthetized dogs during anemic and hypoxic hypoxía. Am. J. Physiol. 209: 604 (1965)

3. Cain, S. M.: Oxygen delivery and uptake in dogs during anemic and hypoxic hypoxia. J. Appl. Physiol.: Respirat. Environ. Exercise Physiol.. 42: 228 (1977).
4. Cain. S. M. and Chapler, C. K.: Oxygen extraction by canine hindlimb during hypoxic hypoxia. J. Appl. Physiol.: Respir. Environ. Exer. Physiol. 46: 1023 (1979).

5. Cross. K. W.. Dawes. G. S. and Mott. J. C.: Anoxia, oxygen consumption and cardiac output in newborn lambs and aduft sheep. J. Physiol.. 146: 316 (1959).

6. Delivoria-Papadopoulos. M.. Martens. R. J.. Oski. F. A.. and Forester. R. F: II: Effect of oxygen-hemoglobin affinity on oxygen consumption and cardiac output of newborn piglets following exchange transfusion. Pediatr. Res. (abstraci) 6: 342 (1972).

7. Downing, S. E. and Rocamora, J. M.: Cardiovascular responses to hypoxemia and acidemia in the intact anesthetized lamb. Yale J. Biol. Med., 40: 296 (1968).

8. Finch, C. A. and Lenfant, C.: Oxygen transport in man, N. Engl. J. Med., 286 407 (1972)

9. Fisher, D. J. Heymann. M. A. and Rudolph. A. M.: Fetal myocardial oxvgen and carbohydrate consumption during acutely induced hypoxemia. Am. J. Physiol.. 242: H657 (1982)

10. Fisher. D. J., Hevmann. M. A., and Rudolph. A. M.: Myocardial consumption of oxygen and carbohydrates in newborn sheep. Pediatr. Res, 15:843 (1981).

11. Gottuso, M. A. Williams, M. I.. and Oski, F. A.: The role of exchange transfusions in the management of low-birth-weight infants with and without severe respiratory distress syndrome. J. Pediatr.. 89: 279 (1976).

12. Hill. J. R.: The oxygen consumption of new-born and adult mammals. Its dependence on the oxvgen tension in the inspired air and on the environmental temperature. J. Physiol. 149: 346 (1959).

13. Hoffman. 3. I. E: Determinants and prediction of transmural myocardial perfusion. Circulation, 58: 381 (1978).

14. Huckabee, W. E.: Relationships of pyruvate and lactate during anaerobic metabolism. III. Effect of breathing low-oxygen gases. J. Clin. Invest.. 37 . $264(1958)$.

15. Jones. M. D.. Traystman, R. J., Simmons. M. S.. and Molteni. R. A.: Effects of changes in arterial $\mathrm{O}_{2}$ content on cerebral blood flow in the lamb. Am. J Physiol. 240: $\mathrm{H} 209$ (1981)

6. Klopfenstein. H. S. and Ruldoph. A. M.: Postnatal changes in the circulation and responses to volume loading in sheep. Circ. Res. 42:839(1978).

17. Kontos, H. A. and Lower. R. R.: Role of beta-adrenergic receptors in the circulatory response to hypoxia. Am. J. Physiol., 217: 756 (1969).

8. Kontos. H. A.. Mauck. H. P.. Jr.. Richardson, D. W.. and Patterson. J. L.. Jr. Mechanism of circulatory responses to svstemic hypoxia in the anesthetized dog. An. J. Physiol., 209: 397 (1965).

19. Lahiri. S.. Mulligan, E.. Nishino. T.. Mokashi. A.. and Davies, R. O.: Relative responses of aortic body and carotid body chemoreceptors to carboxyhem oglobinemia. J. Appl. Physiol.: Respir. Environ. Exer. Physiol.. 50: 580 (1981).

20. Lee. J. C. Halloran, K. H., Taylor. J. F. N.. and Downing. S. E.: Coronary flow and myocardial metabolism in newborn lambs: effects of hypoxia and acidemia. Am. J. Physiol., 224: 1381 (1973)

21. Levison. H. Delivoria-Papadopoulos. M., and Swyer. P. R.: Variations in oxygen consumption in the infant with hypoxacmia due to cardiopulmonary disease. Acta Paediatr. Scand.. 54:369 (1965).

22. Lister, G. Walter. T. K. Versmold. H. T. Dallman. P. R., and Rudolph. A. M.: Cardiovascular and hematologic determinants of oxygen delivery: developmental changes in lambs. Am. J. Physiol., 237(6): H668 (1979)

23. Parer, J. T., Jones. W. D.. and Metcalfe. J.: A quantitative comparison of oxygen transport in sheep and human subjects. Respir. Physiol. 2: 196 (1967).

24. Stahiman, M. Gray, J., Young. W. C.. and Shephard. F. M.: Cardiovascula response of the neonatal lamb to hypoxia and hypercapnia. Am. J. Physiol. 2/3: $899(1967)$

25. Tukey, J. W.: Some thoughts on clinical trials especially problems of multiplicity. Science. 198: 679 (1977).

26. Turek. Z.. Kreuzer, F.. and Ringnalda, B. E. M.: Blood gases at several kevel of oxygenation in rats with a left-sided blood oxygen dissociation curve. Pflugers Arch., 376: 7 (1978).

27. Woodson, R. D.: Physiological significance of oxvgen dissociation curve shifts. Crit Care Med 7: 368 (1979).

28. Woodson, R. D. Wills. R. E. and Lenfanı, C.: Effect of acute and established anemia on $\mathrm{O}_{2}$ transport at rest. submaximal and maximal work. J. Appl. Physiol.: Respir. Environ. Exer. Physiol.. 44: 36 (1978).

29. The author is grateful to Ms. Mary Scott Reding and Ms. Donna Landorf fo assistance in preparing the manuscript, to Ms. Kristine Frick and Ms. Marvanne Kichuk for technical assistance. and to Drs. Edward Milfer and Joseph Bove for handling and preparing the blood products, and Pall Biomedical Products for supplying filters for transfusion.

30. Requests for reprints should be addressed to: George Lister. Pediatric Cardiology Yale University School of Medicine. P.O. Box 3333. New Haven. Connecticut 06510

31. Work was supported in part by grants from the Charles H. Hood Foundation and the Connecticut Chapter of the American Hean Association. Dr. Liste is a recipient of a New Investigators Research Award. HD 15834.

32. Received for publication October 22. 1982

33. Accepted for publication May 13,1983. 